\title{
A series-connected switched source and an H-bridge based multilevel inverter
}

\author{
Siva Pachipala ${ }^{1}$, Amarsrinadh Guda ${ }^{2}$, Mentimi Sandeep Babu ${ }^{3}$, Veeranarayana B. ${ }^{4}$, \\ K. V. S. Ramachandra Murthy ${ }^{5}$, Abhilash Tirupathi ${ }^{6}$ \\ 1,2,3,4,5 Department of Electrical Engineering, Aditya Engineering College, Surampalem, India \\ ${ }^{6}$ Department of Electrical Engineering, Accendere Knowledge Management Services, CL Educate Ltd., New Delhi, India
}

\begin{tabular}{l} 
Article Info \\
\hline Article history: \\
Received Jan 7, 2021 \\
Revised Aug 30, 2021 \\
Accepted Sep 17, 2021 \\
\hline
\end{tabular}

Keywords:

H-bridge

Multilevel inverter

Pulse-width modulation

\begin{abstract}
An inverter circuit is promoted in this paper, using series-connected switched dc sources along with an H-bridge circuit with optimized circuit elements like switching devices and diode clamped (DC) sources. This configuration uses DC supplies that can be strung together in series to create a significant voltage level. This topology consists of two parts, namely: 1) level production part and 2) polarity production part. The combination of some of the dc sources and switching devices completes the level production part. The H-bridge in the presented structure produces the polarity generation part. The DC-link capacitors are not needed in this design. There is a full presentation of the operating modes and modeling process of the proposed converter. Finally, in the MATLAB/SIMULINK setting the proposed topology is simulated and output current and voltage results have been examined.
\end{abstract}

This is an open access article under the CC BY-SA license.

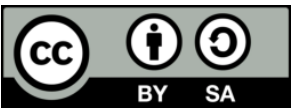

\section{Corresponding Author:}

Abhilash Tirupathi

Department of Electrical and Electronics Engineering

Accendere Knowledge Management Services, CL Educate Ltd

Anna Nagar West Extension, Chennai, Tamil Nadu 600101, India

Email: abhilash.tripuathi@accendere.co.in

\section{INTRODUCTION}

Series-connected switched diode clamped-anode clamped (DC-AC) converters are highly flexible and modular in the family of multilevel inverters. In this group, "cascaded H-bridge (CHB)" converters 11]-[3] are the classical and traditional types. CHB converters have the advantages of equal voltage stress in symmetrical configurations, easy to add/remove the H-bridges to increase/decrease the number of output voltage levels. Multilayer insulation (MLI) technology is spreading to several areas such as AC drives, static reactive compensators, micro-grid systems and renewable energy sources [4]-[6]. The "neutral point clamped (NPC)" or "diode clamped (DC)", "flying capacitor clamped (FCC)", and CHB converters [7]-[9] are established as standard topologies in the MLI family. In these configurations, the device count increases exponentially w.r.t the number of levels in the output voltage, the requirement of unequal voltage ratings of the clamping diodes, unequal capacitor size and a greater number of dc sources puts limitations on these topologies. Several new MLI configurations with the intention of avoiding the drawbacks in the standard topologies were proposed in the literature for several applications [10], [11]. In recent times, cascaded converters are attracting attention from industries as well as academia. Several such "voltage source inverters (VSIs)" were proposed in the literature [12]-[15] by employing several combinations of switches, DC power supplies. The converter has the advantages of reducing the number of components and reduced blocking voltage over the switching units to reduce the cost. In this configuration, the rest of the paper is arranged is being as: section 2 describes work and operating modes, section 3 presents the 
modulation theory for generating the necessary output voltage, section 4 demonstrates the justification by different types of modulation index of the proposed converter, and section 5 concludes finally.

\section{SYSTEM CONFIGURATION}

Figure 1 shows the suggested converter. It's essentially a single-phase AC power supply voltage at nine levels. The converter uses four isolated powers supplied and eight bi-directional conducting switches. Although the switching systems have two-directional driving characteristics, they only block the voltage in one direction because of anti-parallel diodes. The proposed architecture can leverage four different DC sources produced either from battery systems or photovoltaic (PV) systems.

The switching conditions of positive and negative zero voltage crossings are shown in Figures 2(a) and 2(b) respectively. The output voltage at a positive zero-crossing is represented by the symbol $\mathrm{V}_{0}=0^{+}$and similarly $\mathrm{V}_{0}=0^{-}$represents the output voltage negative zero-crossing. It is necessary to apply both switching states equally in direction to keep the temperature, increase in entirely switches, and all of the switching devices for being equal. A positive-level voltage is generated entire the outcome side of the converter represented in Figure 3, which is the operation of the converter under consideration. As shown in Figure 3(a), the power semiconductor devices (IGBTs) $S_{1}, S_{5}$, and $S_{8}$ operate in the same operating mode as when $V_{0}=V_{d c}$ is generated. This operating mode causes the IGBTs $S_{2}, S_{5}$, and $S_{8}$ to conduct. In Figure 3(b) generates $V_{0}=2 V_{d c}$, and the IGBTs $S_{2}, S_{5}$, and $S_{8}$ conduct in this operating mode and Figure 3(c) depicts the maximum voltage of $V_{0}$ $=3 \mathrm{~V}_{\mathrm{dc}}$. It indicates that the IGBTs $\mathrm{S}_{3}, \mathrm{~S}_{5}$, and $\mathrm{S}_{8}$ are operational in this operating mode. Figure 3(d) depicts the maximum voltage of $V_{0}=4 V_{d c}$, which indicates that the IGBTs $S_{4}, S_{5}$, and $S_{8}$ are operational in this operating mode. Figure 4 illustrates the different working converter's modes that are used toward generate negative output voltage levels. As given in Figure 4(a), when $V_{0}=-V_{d c}$ is generated. The IGBTs $S_{4}, S_{1}, S_{6}$ and $S_{7}$ are activated in this operating mode. Figure $4(\mathrm{~b})$ shows the output voltage $V_{0}=-2 V_{d c}$, which corresponds to the time period during which the IGBTs $S_{2}, S_{6}$, and $S_{7}$ are turned on. During this interval, the IGBTs $S_{3}, S_{6}$, and $S_{7}$ are turned on because of the output voltage $V_{0}=-3 V_{d c}$ produced by Figuer $4(c)$. The output voltage $V_{0}=-4 V_{d c}$ is shown in Figure $4(d)$, and the IGBTs $S_{4}, S_{6}$ and $S_{7}$ are turned on throughout this time period.

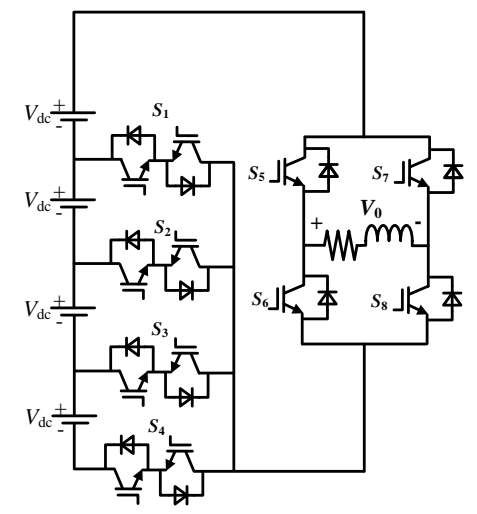

Figure 1. Schematic diagram of the proposed module

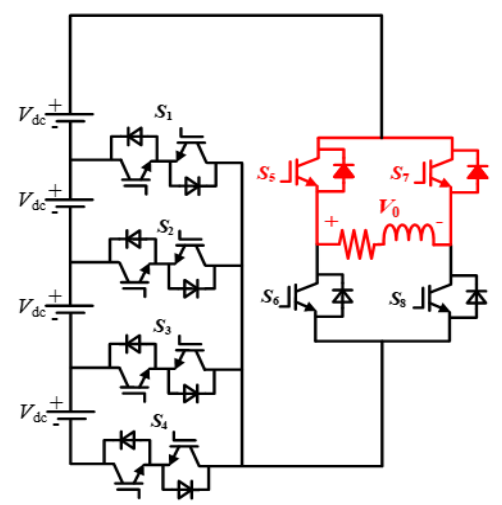

(a)

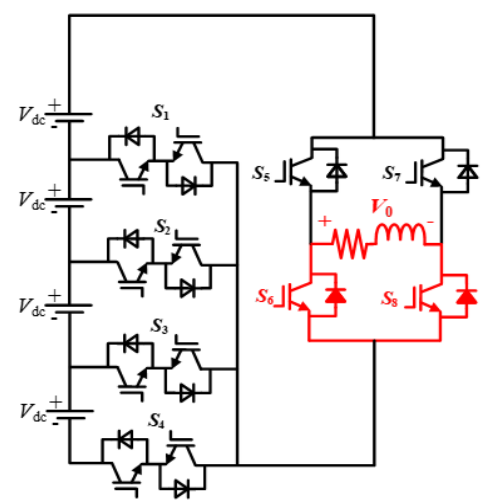

(b)

Figure 2. Zero crossover operating modes; (a) $V_{0}=0^{+}$, (b) $V_{0}=0^{-}$ 


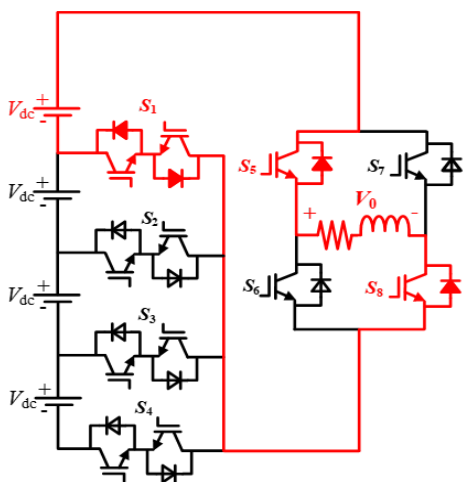

(a)

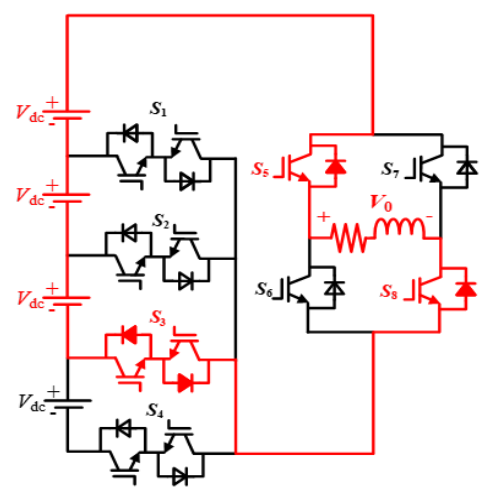

(c)

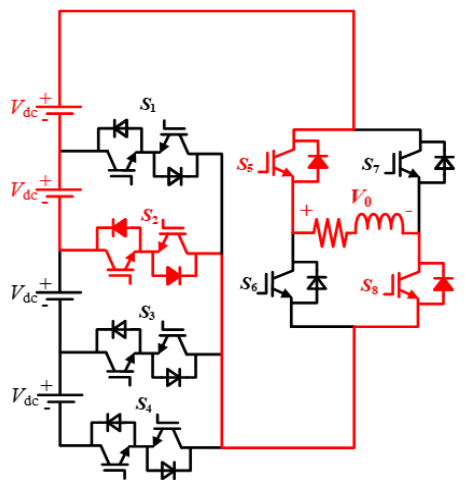

(b)

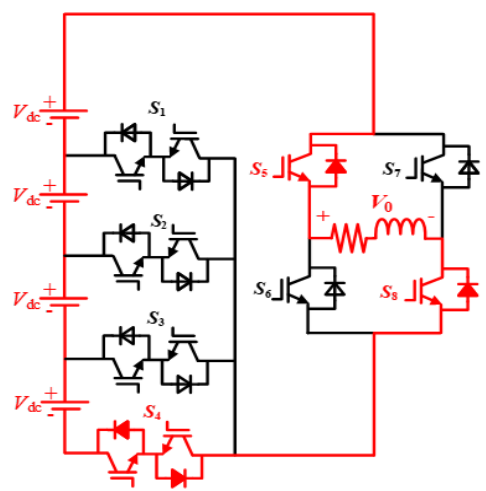

(d)

Figure 3. Positive-level operating modes; (a) $V_{0}=V_{\mathrm{dc}}$, (b) $V_{0}=2 V_{\mathrm{dc}}$, (c) $V_{0}=3 V_{\mathrm{dc}}$, (d) $V_{0}=4 V_{\mathrm{dc}}$

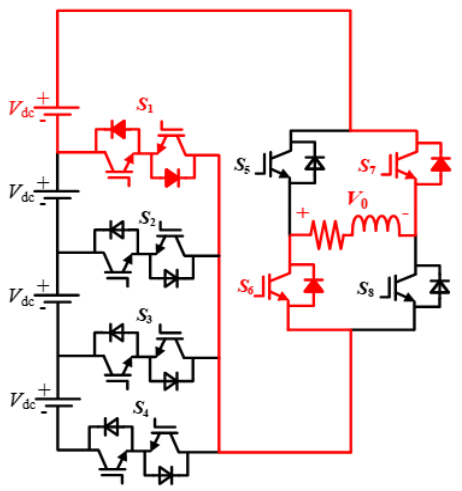

(a)

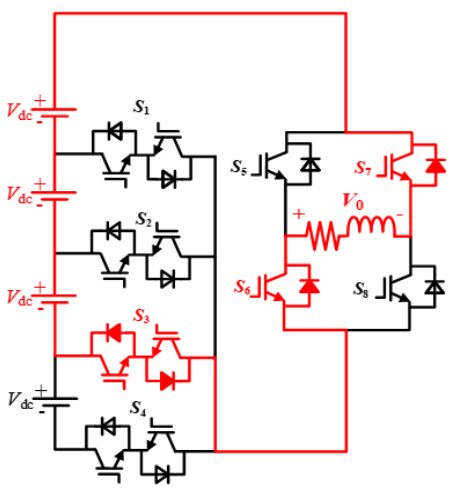

(c)

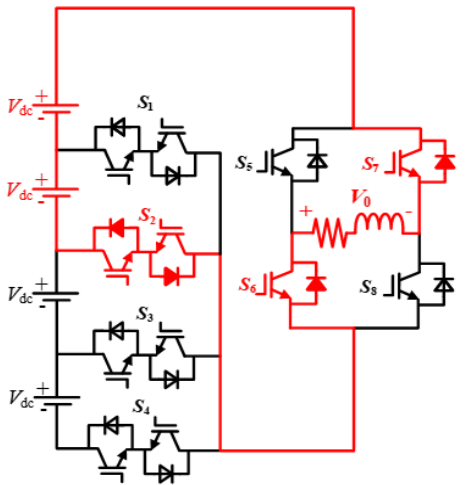

(b)

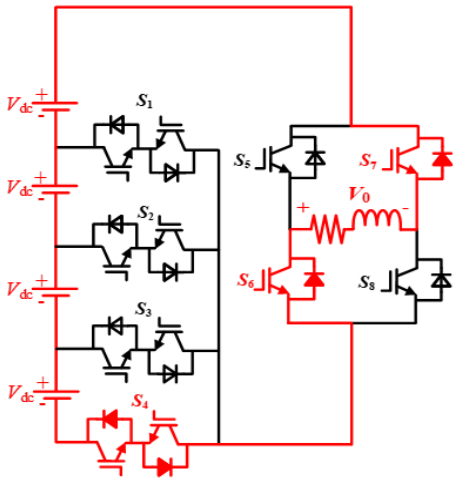

(d)

Figure 4. Negative voltage levels for operation modes; (a) $V_{0}=-V_{\mathrm{dc}}$, (b) $V_{0}=-2 V_{\mathrm{dc}}$, (c) $V_{0}=-3 V_{\mathrm{dc}}$, (d) $V_{0}=-4 V_{\mathrm{dc}}$ 


\section{MODULATION TECHNIQUE}

For the purpose of providing a more accurate explanation of the switching conditions and on and off modes of the switches in the presented converter at various output voltage values is given in Table 1. Figure 1 IGBTs' on/off states are indicated and shwon Table 1 with 1 and 0 respectively. Examine that the H-bridge switches $\mathrm{S}_{5}, \mathrm{~S}_{6}, \mathrm{~S} 7$, and $\mathrm{S}_{8}$ are running at lower switching frequency than the other H-bridge switches, as a result of which the switching losses are reduced. Figure 5 shows the modulation method [16]-[18] in the suggested topology for the generation of gate pulse to IGBTs [16]-[18]. 8-triangular waveforms are stacked on top of each other with a sinusoidal waveform on top. The sine wave is known as a wave reference and carrier wave is represented by triangular wave.

The reference wave is impacted by each carrier wave at certain intervals that are shown as 1, 2, 3, 4, 1', 2', 3', and 4'. Therefore, the pulses produced are P1-P4 and N1-N4 because of the interactions among the carrier and reference waves. These pulses are efficiently used to generate the nine-level output voltage via logical gate circuits. In the following terms is defined the "modulation index (M.I.)" that represents the number of output levels [19]:

$$
\text { M.I. }=\frac{V_{0 p e a k}}{4 \times V_{d c}}
$$

Table 1. Switching sequence of the inverter

\begin{tabular}{cllllllll}
\hline Output Voltage level $\left(V_{\mathrm{O}}\right)$ & $\mathrm{S} 1$ & $\mathrm{~S} 2$ & $\mathrm{~S} 3$ & $\mathrm{~S} 4$ & $\mathrm{~S} 5$ & $\mathrm{~S} 6$ & $\mathrm{~S} 7$ & $\mathrm{~S} 8$ \\
\hline $4 V_{\mathrm{dc}}$ & 0 & 0 & 0 & 1 & 1 & 0 & 0 & 1 \\
$3 V_{\mathrm{dc}}$ & 0 & 0 & 1 & 0 & 1 & 0 & 0 & 1 \\
$2 V_{\mathrm{dc}}$ & 0 & 1 & 0 & 0 & 1 & 0 & 0 & 1 \\
$V_{\mathrm{dc}}$ & 1 & 0 & 0 & 0 & 1 & 0 & 0 & 1 \\
$0^{+}$ & 0 & 0 & 0 & 0 & 1 & 0 & 1 & 0 \\
$0^{-}$ & 0 & 0 & 0 & 0 & 0 & 1 & 0 & 1 \\
$-V_{\mathrm{dc}}$ & 1 & 0 & 0 & 0 & 0 & 1 & 1 & 0 \\
$-2 V_{\mathrm{dc}}$ & 0 & 1 & 0 & 0 & 0 & 1 & 1 & 0 \\
$-3 V_{\mathrm{dc}}$ & 0 & 0 & 1 & 0 & 0 & 1 & 1 & 0 \\
$-4 V_{\mathrm{dc}}$ & 0 & 0 & 0 & 1 & 0 & 1 & 1 & 0 \\
\hline
\end{tabular}
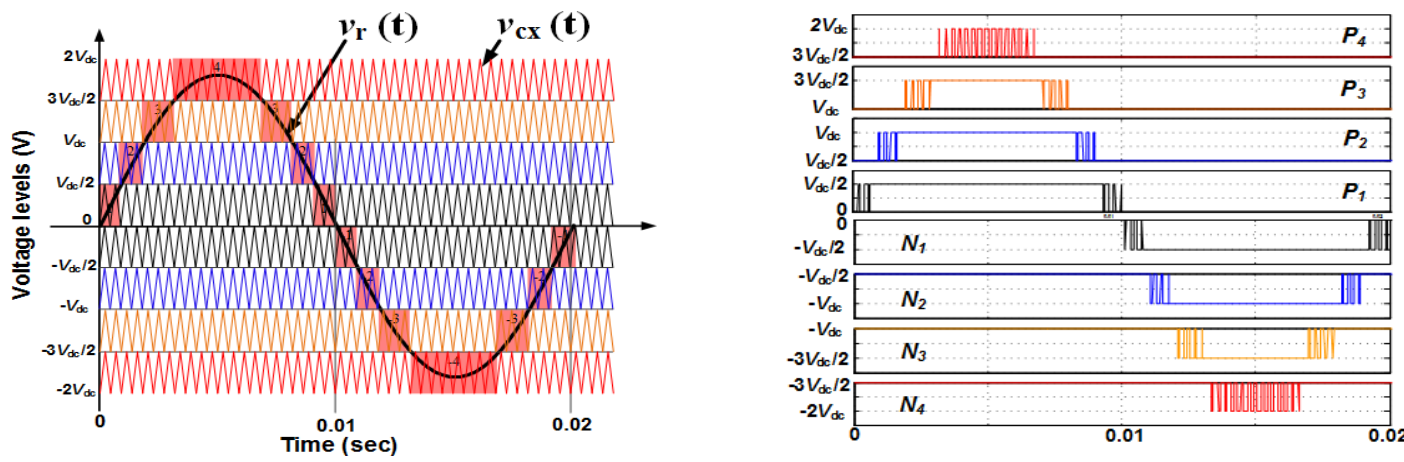

Figure 5. Sine-triangle comparison PWM scheme

\section{SIMULATION RESULTS}

The proposal's functionality is demonstrated using "MATLAB" simulation [20]-[22] and is validated to show how it will perform. According to the simulation, the resulting output voltage is expected to be 230 volts and 50 Hertz. Parameters evaluated for simulation work also feature alternative values in Table 2 . The M.I. of 0.9 may be seen in Figure 6(a), where it shows the inverter output voltage and the matching current waveforms. The 9-level voltage signal is shown, along with the current. It is evident that the M.I. decrease reduces the output voltage maximum value $\left(\mathrm{V}_{\text {Opeak }}\right)$. Figure $6(\mathrm{~b})$ shows the output waveform spectrum of the FFT at various M.I values. When the converter is modulated at $0.9, \mathrm{~V}_{\text {opeak }}$ is detected as $361 \mathrm{~V}$, with the "total harmonic distortion (THD)" being $16.6 \%$ and the harmonic spectrum of the current output waveforms is displayed in Figure 6(c). A value of 6.4 A with a modulation of 0.9 and THD of around $0.5 \%$ is observed in the $\mathrm{I}_{0 \text { peak }}$ value. The current waveform and "inverter output voltage" for an M.I. is displayed at 0.7 in Figure 7(a) and the associated load current for that seven-level output voltage waveform. It is evident that the M.I. decrease reduces the output voltage maximum value $\left(\mathrm{V}_{\text {opeak }}\right)$. The drop in M.I. leads to a growth in THD because the voltage voltage level in Figure 7(b) is reduced as shown (b). The voltage, $\mathrm{I}_{0 \text { peak }}$ value, falls by 
around 0.7 in M. I., the $\mathrm{I}_{0 \text { peak }}$ value, and THD is around $0.6 \%$ in Figure 7(c) (see Appendix). The voltage, $\mathrm{I}_{0 \text { peak }}$ values are decreased by about $0.6 \%$ [23]-[25].

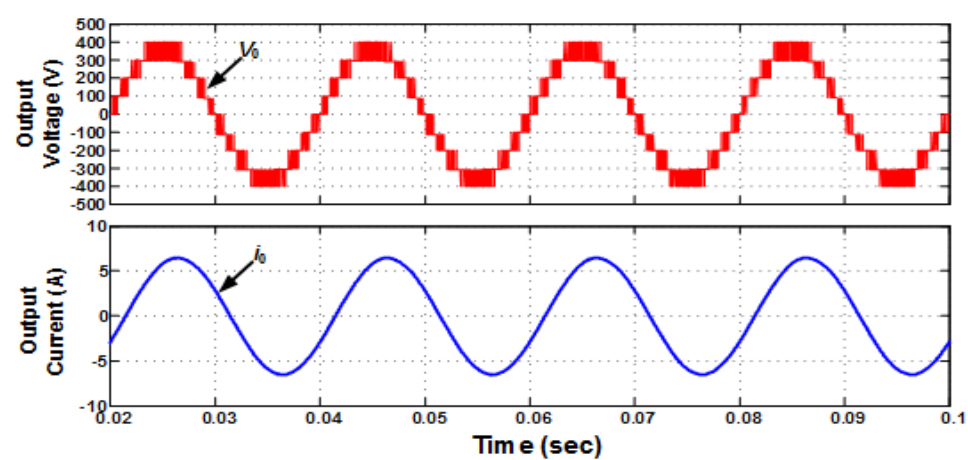

(a)

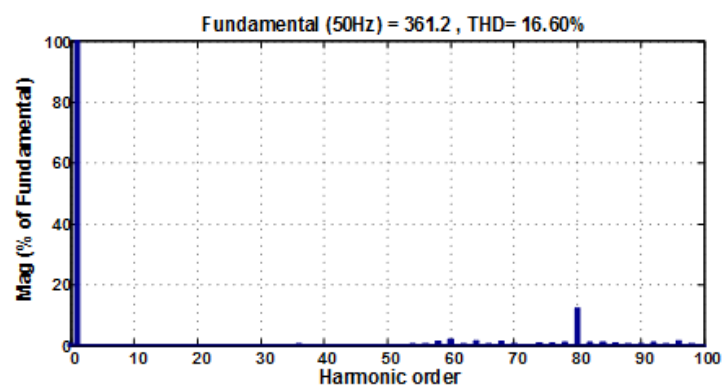

(b)

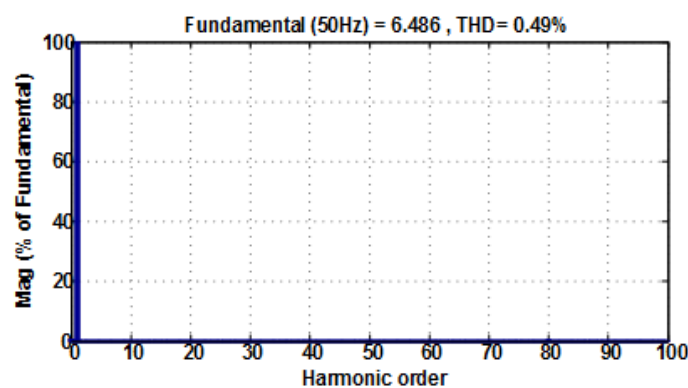

(c)

Figure 6. Simulink results of the converter at a peak reference of 0.9 ; (a) converter voltage and current waveforms at the output, (b) FFT spectrum of $V_{0}$, (c) FFT analysis of $I_{0}$

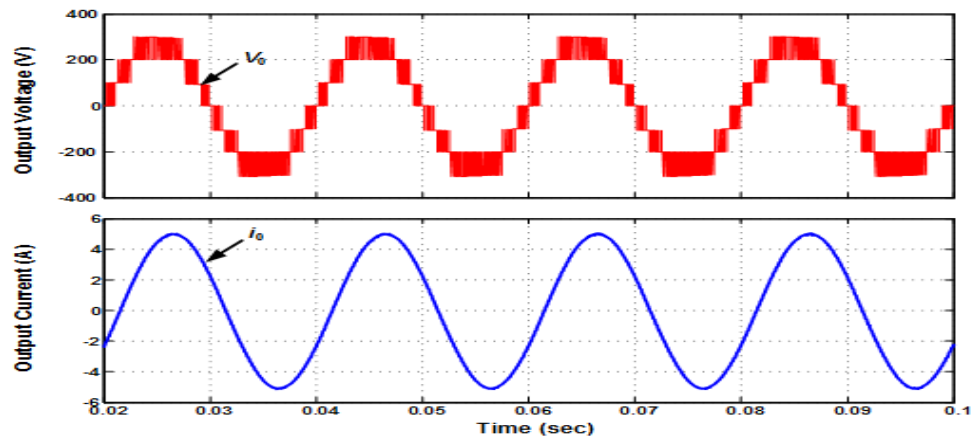

(a)

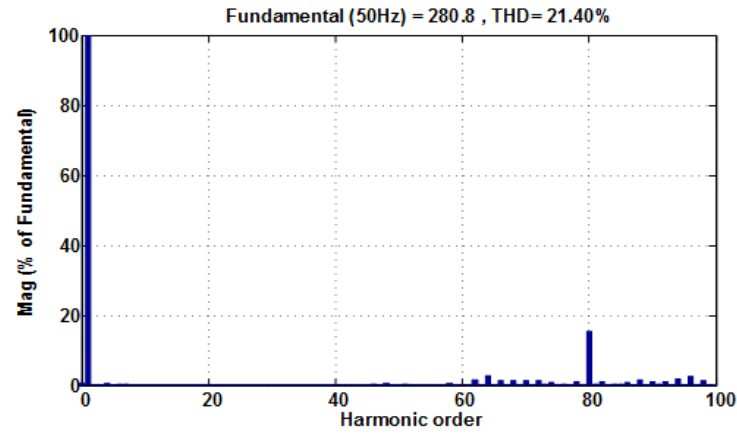

(b)

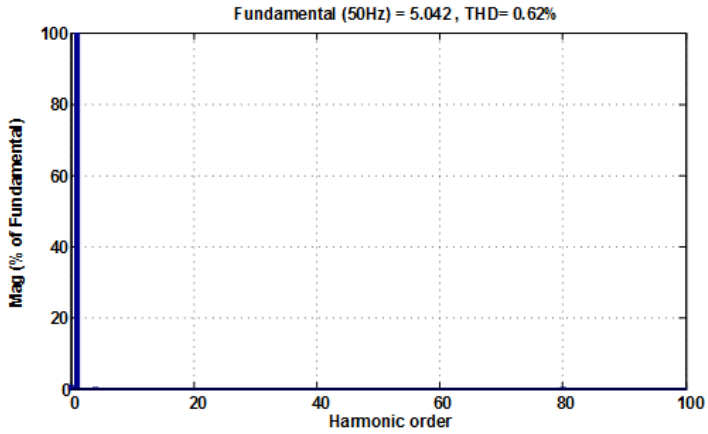

(c)

Figure 7. Simulink outcome; (a) converter voltage and current waveforms at the output, (b) FFT spectrum of $V_{0}$, (c) FFT analysis of $I_{0}$ 


\begin{tabular}{lcc}
\multicolumn{3}{c}{ Table 2. Design spefcations } \\
\hline Specfications & \multicolumn{2}{c}{ Values } \\
& M.I. $=0.9$ & M.I. $=0.7$ \\
\hline$V_{\text {dc }}(\mathrm{V})$ & $200 \mathrm{~V}$ & $200 \mathrm{~V}$ \\
$\mathrm{P}_{\text {output }}(\mathrm{W})$ & 1070 & 650 \\
$V_{0}(\mathrm{~V})$ & 260 & 203 \\
$I_{0}(\mathrm{~A})$ & 4.5 & 3.5 \\
Switching frequency $\left(f_{\mathrm{sw}}\right)$ & $4 \mathrm{kHz}$ & $4 \mathrm{kHz}$ \\
Fundamental frequency $\left(f_{\mathrm{m}}\right)$ & $50 \mathrm{~Hz}$ & $50 \mathrm{~Hz}$ \\
\hline
\end{tabular}

\section{CONCLUSION}

The focus of this article is on a novel MLI topology used in the nine-level DC-AC converter family. The presented architecture is the most active group recently made by switched dc source cell and $\mathrm{H}$-bridge, in order to optimise the number of segments in a specific inverter topology. To generate the zero, positive, and negative levels, a complete analysis as well as operating modes have been provided. In the suggested architecture, the H-bridge switches run at an essential frequency, and do so at a lower switching frequency. This results in switching losses that are significantly lower than those of numerous MLI designs, which in turn increases the overall efficiency of the presented system, as presented in the topology. The sinusoidal PWM approach, which is the most effective and least complex, is used to create the firing pulses. For the configuration, it has been demonstrated that the findings of the MATLAB/SIMULINK simulations are true for modulation indexes of 0.9 and 0.7. This graph depicted the total harmonic distortion (THD) content of the output current and voltage waveforms, and the output voltage THD content was found to be significantly lower than the industry standard limits.

\section{REFERENCES}

[1] S. Rahman and F. C. Lee, "Computer Simulations of Optimum Boost and Buck-Boost Converters," in IEEE Transactions on Aerospace and Electronic Systems, vol. AES-18, no. 5, pp. 598-608, September 1982, doi: 10.1109/TAES.1982.309272.

[2] M. Marchesoni, "High-performance current control techniques for application to multilevel high-power voltage source inverters," in IEEE Transactions on Power Electronics, vol. 7, no. 1, pp. 189-204, January 1992, doi: $10.1109 / 63.124591$.

[3] G. Carrara, S. Gardella, M. Marchesoni, R. Salutari and G. Sciutto, "A new multilevel PWM method: a theoretical analysis," in IEEE Transactions on Power Electronics, vol. 7, no. 3, pp. 497-505, July 1992, doi: $10.1109 / 63.145137$.

[4] S. Szuba, "An approach to the design of energy storage reactors for DC-to-DC switching power converters using ferrite structures," in IEEE Transactions on Magnetics, vol. 16, no. 5, pp. 1271-1278, September 1980, doi: 10.1109/TMAG.1980.1060798.

[5] P. R. K. Chetty, "CIECA: Application to Current Programmed Switching Dc-Dc Converters," in IEEE Transactions on Aerospace and Electronic Systems, vol. AES-18, no. 5, pp. 538-544, September 1982, doi: 10.1109/TAES.1982.309266.

[6] J.-S. Lai and F. Z. Peng, "Multilevel converters-a new breed of power converters," in IEEE Transactions on Industry Applications, vol. 32, no. 3, pp. 509-517, May-June 1996, doi: 10.1109/28.502161.

[7] F. Z. Peng, J.-S. Lai, J. W. McKeever and J. V. Coevering, "A multilevel voltage-source inverter with separate DC sources for static VAr generation," in IEEE Transactions on Industry Applications, vol. 32, no. 5, pp. 1130-1138, September-October 1996, doi: 10.1109/28.536875.

[8] H. Matsuo and F. Kurokawa, "New Solar Cell Power Supply System Using a Boost Type Bidirectinal DC-DC Converter," in IEEE Transactions on Industrial Electronics, vol. IE-31, no. 1, pp. 51-55, February 1984, doi: 10.1109/TIE.1984.350020.

[9] C. T. Rim, G. B. Joung, and G. H. Cho, "Practical switch-based state-space modeling of DC-DC converters with all parasitics," in IEEE Transactions on Power Electronics, vol. 6, no. 4, pp. 611-617, 1991, doi: 10.1109/63.97759.

[10] T. Abhilash, K. Annamalai, and S. V. Tirumala, "A Seven-Level VSI With a Front-End Cascaded Three-Level Inverter and Flying-Capacitor-Fed H-Bridge," in IEEE Transactions on Industry Applications, vol. 55, no. 6, pp. 6073-6088, November-December 2019, doi: 10.1109/TIA.2019.2933378.

[11] B. Wang, X. Zhang, and H. B. Gooi, "An SI-MISO Boost Converter with Deadbeat-Based Control for Electric Vehicle Applications," in IEEE Transactions on Vehicular Technology, vol. 67, no. 10, pp. 9223-9232, October 2018, doi: 10.1109/TVT.2018.2853738.

[12] R. Wai, C. Lin, R. Duan, and Y. Chang, "High-Efficiency DC-DC Converter with High Voltage Gain and Reduced Switch Stress," in IEEE Transactions on Industrial Electronics, vol. 54, no. 1, pp. 354-364, February 2007, doi: 10.1109/TIE.2006.888794.

[13] M. Rasheed, R. Omar, M. Sulaiman, W. A. Halim, and M. M. A. Alakkad, "Analysis of a switching angle calculation by ANN for nine level inverter apply into experimental case study with elimination of lower and higher order harmonics, "Indonesian Journal of Electrical Engineering and Computer Science, vol. 20, no. 2, pp. 948-959, November 2020, doi: 10.11591/ijeecs.v20.i2.pp948-959. 
[14] M. Rasheed, M. M. A. Alakkad, R. Omar, M. Sulaiman, and W. A. Halim, "Enhance the accuracy of control algorithm for multilevel inverter based on artificial neural network," Indonesian Journal of Electrical Engineering and Computer Science, vol. 20, no. 3, pp. 1148-1158, December 2020, doi: 10.11591/ijeecs.v20.i3.pp1148-1158.

[15] C. Restrepo, J. Calvente, A. Cid-Pastor, A. E. Aroudi and R. Giral, "A Noninverting Buck-Boost DC-DC Switching Converter with High Efficiency and Wide Bandwidth," in IEEE Transactions on Power Electronics, vol. 26, no. 9, pp. 2490-2503, September 2011, doi: 10.1109/TPEL.2011.2108668.

[16] K. Kruse, M. Elbo, and Z. Zhang, "GaN-based high efficiency bidirectional DC-DC converter with $10 \mathrm{MHz}$ switching frequency," 2017 IEEE Applied Power Electronics Conference and Exposition (APEC), 2017, pp. 273-278, doi: 10.1109/APEC.2017.7930705.

[17] A. Tsunoda, Y. Hinago, and H. Koizumi, "Level-and Phase-Shifted PWM for Seven-Level Switched-Capacitor Inverter Using Series/Parallel Conversion," in IEEE Transactions on Industrial Electronics, vol. 61, no. 8, pp. 4011-4021, August 2014, doi: 10.1109/TIE.2013.2286559.

[18] J. Wu and C. Chou, "A Solar Power Generation System with a Seven-Level Inverter," in IEEE Transactions on Power Electronics, vol. 29, no. 7, pp. 3454-3462, July 2014, doi: 10.1109/TPEL.2013.2279880.

[19] M. Rasheed, R. Omar, M. Sulaiman, and W. A. Halim, "A modified cascaded h-bridge multilevel inverter based on particle swarm optimisation (PSO) technique," Indonesian Journal of Electrical Engineering and Computer Science, vol. 16, no. 1, pp. 41-45, October 2019, doi: 10.11591/ijeecs.v16.i1.pp41-51.

[20] M. Sujatha and A. K. Parvathy, "Improved reliable multilevel inverter for renewable energy systems," Indonesian Journal of Electrical Engineering and Computer Science, vol. 14, no. 3, pp. 1141-1147, June 2019, doi: 10.11591/ijeecs.v14.i3.pp1141-1147.

[21] T. Abhilash, A. Kirubakaran, and V. T. Somasekhar, "A new structure of three-phase five-level inverter with nested two-level cells," International Journal of Circuit Theory and Applications, vol. 47, no. 9, pp. 1435-1445, May 2019, doi: 10.1002/cta.2648.

[22] T. Abhilash, A. Kirubakaran, and V. T. Somasekhar, "A new hybrid flying capacitor based single phase nine-level inverter," International Transactions on Electrical Energy Systems, vol. 29, no. 12, pp. 1-15, July 2019, doi: 10.1002/2050-7038.12139.

[23] L. Priya, L. S. Hansitha, K. Rajesh, U. S. S. Polaraju and N. Rajesh. "Simulation and Analysis of Seven-Level Voltage Source Inverter." in Soft Computing Techniques and Applications, Springer, Singapore, 2021, pp. 111-120, doi: 10.1007/978-981-15-7394-1_10.

[24] T. A. Meynard, M. Fadel and N. Aouda, "Modeling of multilevel converters," in IEEE Transactions on Industrial Electronics, vol. 44, no. 3, pp. 356-364, June 1997, doi: 10.1109/41.585833.

[25] K. V. Patil, R. M. Mathur, J. Jiang and S. H. Hosseini, "Distribution system compensation using a new binary multilevel voltage source inverter," in IEEE Transactions on Power Delivery, vol. 14, no. 2, pp. 459-464, April 1999, doi: 10.1109/61.754089. 